Shachaf, P. (2005). Bridging cultural diversity through e-mail. Journal of Global Information Technology Management, 8(2), 46-60.

\title{
Bridging cultural diversity through e-mail
}

\author{
Pnina Shachaf \\ School of Library and Information Science, Indiana University 1320 East Tenth Street, LI005A, \\ Bloomington, IN 47405-3907. shachaf@indiana.edu
}

\begin{abstract}
The implementation of global virtual teams presents modern organizations with significant challenges, such as a multicultural workforce and the use of information and communication technology. Cultural diversity increases teamwork complexity and may weaken a team's effectiveness and jeopardize its viability. Selection and implementation of appropriate information technology may facilitate group processes and overcome potential barriers created by team heterogeneity. This study illustrates how e-mail mitigates intercultural miscommunication. Interviews with 41 global virtual team members in nine countries, who were employed by a multinational corporation, were transcribed and analyzed. The use of e-mail improves language accuracy, mitigates intercultural miscommunication resulting from verbal differences among team members, and eliminates nonverbal differences. Only future studies can determine the extent of this mitigation.
\end{abstract}

\section{INTRODUCTION}

Unlike traditional teams, virtual teams routinely cross boundaries, using communication technology to link members. A virtual team is "a group of people who work interdependently with a shared purpose across space, time, and organization boundaries using technology" (Lipnack \& Stamps, 1997, p. 18). This definition implies crossing over organizational or national boundaries and also occasionally over functional boundaries (Jarvenpaa \& Leidner, 1999). Global virtual teams (GVTs) are internationally distributed, culturally diverse, and geographically dispersed work teams.

The increased use of GVTs creates opportunities as well as challenges for traditional management theories and practices. Employing GVTs allows organizations to combine the expertise needed for task performance, regardless of geographic location or travel costs and restrictions (Kirkman, Rosen, Gibson, Tesluk, \& McPherson, 2002).

Although there are clear advantages to instituting GVTs, these teams face greater communication challenges than face-to-face teams (Watson-Manheim \& Belanger, 2002). Specifically, traditional communication mechanisms are lost or distorted, and vocal and nonverbal communication cues are altered (Kayworth \& Leidner, 2001). In addition, because of team members' locations in multiple time zones, logistics are more complex; scheduling meetings and travel is very difficult. As a result of the conditions of virtual teamwork, building trust among GVT members becomes an additional challenge for GVTs (Jarvenpaa \& Leidner, 1999), as does overcoming feelings of isolation and detachment (Kirkman et al., 2002). Cultural diversity further increases teamwork complexity and may weaken a team's effectiveness and jeopardize its viability. Although cultural diversity has potential advantages for team effectiveness, 
heterogeneity presents team members with tremendous challenges (Dube \& Pare, 2001).

In a context of culturally diverse teams, the participation of team members who must speak a foreign language may be reduced; however, technological mediation enables equalization and increased participation (Dube \& Pare, 2001). Not only language barriers, but also differing verbal and nonverbal styles of team members affect intercultural communication (Gudykunst \& Ting-Toomey, 1988). Although nonverbal miscommunication does not occur via e-mail, differences in verbal style can either increase miscommunication or improve communication among team members.

It is essential to gain a better understanding of the effects of cultural diversity and virtuality on team effectiveness (Dafoulas \& Macaulay, 2001; Dube \& Pare, 2001; Evaristo, 2003; Jarvenpaa \& Leidner, 1999). The effect of cultural diversity may be diluted, similar, or amplified in the virtual setting as compared with a traditional setting. In particular, it is possible that selection and implementation of the appropriate types of information technology could facilitate group processes and overcome potential barriers created by heterogeneity in GVTs (Dube \& Pare, 2001).

This study was designed to discover how members of GVTs perceive the influence of e-mail use on intercultural communication and to understand how e-mail mitigates or amplifies the impact of cultural diversity on team effectiveness. A qualitative, naturalistic approach was applied in order to collect from participants, in their everyday settings, descriptions of how they understand and manage actions related to their operations.

Figure 1 illustrates the framework of this study. The model suggests that team communication in GVTs is influenced by the heterogeneous composition of team members. Team communication is also influenced by the use of e-mail for intercultural communication among heterogeneous team members. GVT communication is both intercultural and computer mediated, and GVT communication is an essential factor in the success of the team. In the event of distorted communication, team performance and satisfaction of individual team members are jeopardized. Thus, the next section reviews the literature on intercultural communication, e-mail mediated communication, and cultural diversity of GVTs.

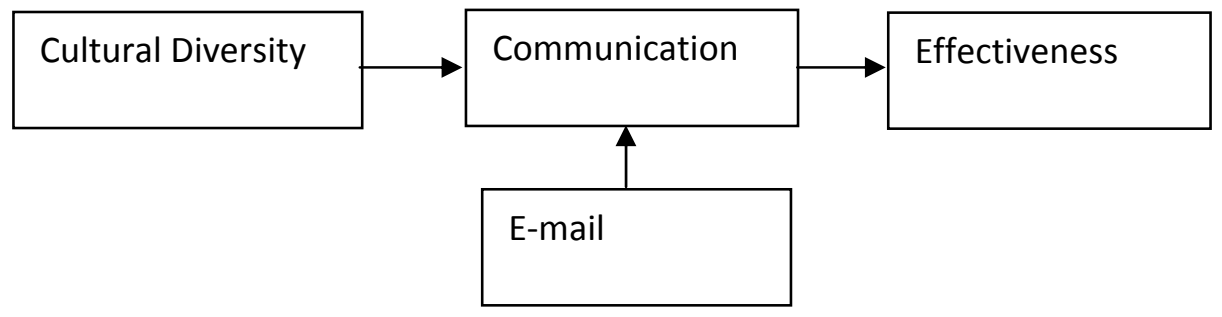

Figure 1. A model of intercultural mediated communication

\section{LITERATURE REVIEW}

Very little of the research on dispersed virtual teams has addressed cultural diversity (Evaristo, 2003; Jarvenpaa \& Leidner, 1999). Researchers have identified differences in technology use and in perceptions of task technology fit among eastern and western cultures. For instance, O. Lee (2002) found that patterns of e-mail use vary 
among eastern and western cultures because of cultural differences. Massey, Hung, Montoya-Weiss and Ramesh (2001) observed significant differences in the perception of task technology fit between virtual team members from the United States, Asia, and Europe. Similarly, Frank and Toland (2002) reported that students from an individualistic culture (Australia) tended to use e-mail for communication more than students from a collectivistic culture (Fiji). However, Jarvenpaa and Leidner (1999) found that cultural diversity had no significant influence on trust in virtual teams and hypothesized that the impact of cultural diversity is decreased in the virtual setting.

Previous studies of global teams suggested that cultural diversity has both a positive and negative influence on team effectiveness (Adler, 1997). It is evident that input variables such as group composition have both direct and mediated impacts on group outcomes (Earley \& Mosakowski, 2000; Oetzel, 2001). Earley and Mosakowski found that highly heterogeneous teams and highly homogeneous teams exhibit high levels of productivity, while moderately heterogeneous teams have lower levels of productivity. Other studies concluded that diversity increases effectiveness (Daily \& Steiner, 1998; Daily, Whatley, Ash, \& Steiner, 1996; McLeod \& Lobel, 1992; Watson, Kumar, \& Michaelson, 1993). The results of these studies indicate that cultural diversity enables an increase in creativity due to a wider range of perspectives, more and better ideas, and less groupthink, and that for these reasons, diversity has the potential to increase performance (Adler, 1997). Furthermore, in forcing team members to increase their efforts to understand each others' ideas and arguments, cultural diversity may lead to better ideas, better solutions, and better decisions, and therefore higher productivity. Previous studies found that heterogeneous teams were more creative and more innovative (Daily \& Steiner, 1998) and produced higher quality ideas on brainstorming tasks (McLeod \& Lobel, 1992). In the long run, heterogeneous teams outperformed homogeneous teams in identifying perspectives on a problem and generating alternatives (Watson et al., 1993). These findings suggest that team heterogeneity increases the potential for higher productivity (Daily \& Steiner, 1998; Daily et al., 1996).

Because of the additional communication barriers they face, heterogeneous teams experience higher process losses than homogeneous teams. Since cultural diversity increases the complexity, conflict, confusion, and ambiguity of communication, it sets higher challenges for leaders and team members (Adler, 1997). Therefore, cultural diversity may decrease the actual productivity of the team (Daily \& Steiner, 1998). Research indicates that culturally diverse groups exhibit lower levels of integration and cohesion and that team members lack the shared mental models that would enable understanding among team members (Klimoski \& Mohammed, 1994). The resulting misunderstanding creates mistrust and miscommunication among team members and increases stereotyping-which can lead to an inability to validate ideas and arguments, gain consensus, and reach decisions, and could therefore result in less productivity (Adler, 1997). The most evident aspects of miscommunication are reduced accuracy in communication, slower speech by normative speakers, and translation problems.

Communication among GVT members is especially complex. Not only does it involve cross-cultural communication, but it is also mediated by computers (Jarvenpaa \& Leidner, 1999; Maznevski \& Chudoba, 2000). Therefore, effective communication is particularly critical for success in a virtual setting. In the words of Watson-Manheim and 
Belanger (2002), "Communication is the essential backbone behind virtual work and organizations" (p. 2). The heterogeneous composition of a GVT can lead to distorted communication due to both intercultural miscommunication and the mediation of the communication by e-mail, which is a lean medium.

\section{Patterns in Face-to-Face Interpersonal Communication in Teams}

Cultural differences among GVT members increase the potential barriers that teams face, because individuals from different national and cultural backgrounds communicate differently (Adler, 1997; Gudykunst \& Ting-Toomey, 1988). Team members must speak a common language, typically English; this causes lower participation by non-native speakers, resulting in less relevant input for decision making.

Intercultural communication involves, in addition to language differences, the different verbal and nonverbal styles of team members. Gudykunst and Ting-Toomey (1988) identified four dimensions in verbal style differences in intercultural communication: direct-indirect, elaborate-succinct, personal-contextual, and instrumental-affective. The direct-indirect difference in verbal styles refers to the extent to which people reveal their intentions using explicit verbal communication. Elaboratesuccinct refers to differences in the amount of information provided in communication. Exact style provides exact information, elaborate style provides more than just the required information, and succinct style provides less verbal information while using silence and pauses. A third stylistic difference is that between personal and contextual verbal communication. The contextual style contains formal elements that reflect the social and organizational differences between people and maintains the social context, and the personal style assumes similarity and equality. The fourth difference is that between instrumental and affective-intuitive verbal communication styles. The instrumental style is sender oriented and goal oriented; the affective style is receiver oriented and process oriented.

When global virtual team members communicate with each other, the differences that have been present in face-to-face intercultural communication are mediated by the technology used for communication. It is possible that when team members are using email, these differences in verbal styles will be amplified or mitigated compared to faceto-face communication.

\section{E-mail Mediated Communication}

Electronic communication is an integral part of work today, and the understanding of e-mail interaction increases organizational and team productivity (Jackson, Dawson, \& Darren, 2003). Suchan and Hayzak (2001) observed that team members perceived communication-and particularly media choice-as a strategic activity that had to be planned. E-mail is one of the most commonly used channels for communication among dispersed heterogeneous team members (DeSanctis, Wright, \& Jung, 2001). Hence, asynchronous communications, such as e-mail and discussion forums, are vital when team members are geographically dispersed.

Theories on the use of computers and e-mail for communication among team members include media richness theory (MRT, Daft \& Lengel, 1986), task technology fit (Hollingshead, McGrath, \& O'Connor, 1993), social influence theory (Schmitz \& Fulk, 
1991), and social presence theory (Sproull \& Keisler, 1986). Likewise, A. Lee (1994) and Markus (1994) focused more specifically on e-mail use in an organizational setting.

According to the media richness theory, e-mail is a lean medium, since it conveys little information (Daft \& Lengel, 1986). The inability of the e-mail channel to handle simultaneous multiple cues, two-way communication, and instant feedback can reduce intercultural miscommunication caused by non-verbal communication. E-mail also limits social presence, which is a subjective perception of the realness of other users involved in the communication incident (Sproull \& Keisler, 1986). As the capabilities of the medium to convey visual and nonverbal cues rise, the social presence of individuals increases. Interactions using electronic mail are more impersonalized and task oriented. Sproull and Keisler emphasized the lack of contextual cues when electronic mail is used for communication. Decreasing social cues has a deregulating effect on communication and results in status equalization. For these reasons, e-mail can help overcome diversity challenges.

Schmitz and Fulk (1991) suggested that media perception is in part socially constructed and that the perception of the media channel affects media choice. Media choice is affected by the social process, group and organization patterns, and statements of coworkers, as well as by organizational and team norms of technology use. A. Lee (1994) claimed that richness or leanness is not an inherent property of the electronic mail medium but an emergent property of the interaction of the electronic mail medium with its organizational context. According to Lee, managers are not passive recipients of data but active producers of meanings. Likewise, Markus (1994) challenged the widespread assumption that when it comes to communication media, "the richer the better" (p. 502). Markus emphasized that the social context is more important than the medium itself for communication effectiveness; even a lean medium can be rich if the organizational context supports it. Therefore, it is possible that heterogeneous teams will share the same perception of e-mail if they share the same social context while working together on tasks in a distributed and diverse GVT. This study illustrates socially constructed e-mail use by heterogeneous GVT members.

\section{METHODOLOGY}

The purpose of this study was to develop an understanding of how e-mail mitigates or amplifies the impact of cultural diversity on team effectiveness. In particular, an effort was made to explore the impact of e-mail on intercultural communication. For that purpose, a qualitative, naturalistic approach was used to collect data from participants in their everyday settings and to elicit descriptions of the ways participants understood and managed actions related to their operations.

The source of data was individual open interviews with 41 GVT members; some interview subjects belonged to more than one GVT. Thirty-five participants worked for a Fortune 500 multicultural corporation in the computer industry. The corporation's top management is based in the United States; divisions are located around the globe, with employees in various countries in Asia, Europe, North and South America, and Australia. Nine participants in the study were members of an interorganizational GVT that was created for a research and development project and financed by the European Union under the Information Society Technologies Program. This GVT was spread over six European countries and involved employees of seven organizations; of the 9 team 
members interviewed, 2 were in France, 2 in Germany, 2 in Israel, 1 in the Netherlands, and 1 in the United Kingdom.

Theoretical sampling was applied, finalizing the sample size during data collection; data collection ended as theoretical saturation was attained (Glaser \& Strauss, 1967). The 41 participants in this study were from nine countries of residency, with 1 to 15 participants in each country. The sample include the following numbers of participants per country of residency: 2 in France, 2 in Germany, 14 in Israel, 1 in Italy, 2 in Japan, 2 in the Netherlands, 1 in Switzerland, 2 in the United Kingdom, and 15 in the United States. The data were collected from 16 face-to-face interviews and 25 telephone interviews, which took place over nine months, from June 2002 to February 2003. Thirty of the participants were engaged in software research and development tasks; 11 performed sales and marketing tasks.

An interview protocol with open-ended questions was developed. Participants were asked to describe the context of their work with GVTs and to focus on their use of technology for communication. They were asked to elaborate specifically on their use of e-mail. They were also asked to describe the impact of cultural diversity on their work in GVTs and to elaborate on how technologies, and e-mail in particular, are utilized in this context. They were also asked to describe the impact of cultural diversity on their work in GVTs. Further questions were developed in response to answers the participants gave during the interview. Follow-up questions provided additional explanations and clarification.

After the interviews were transcribed, the text was analyzed using an interpretive approach (Miles \& Huberman, 1994). An inductive approach was used for interpretation and for developing categories from the data. Concepts from the data were then sorted according to the categories. Data analysis focused at the individual level of analysis. The data analysis was supported by the use of NVIVO 1.3 software, which was designed for qualitative analysis by the developers of NUD*ist software.

\section{FINDINGS}

GVT members interviewed in this study used multiple technologies for communicating and sharing information with each other. Participants reported on their use of e-mail, chat, e-meeting, teleconference, and team room, in addition to their faceto-face meetings. The use of media channels was based mainly on corporate-wide use of Lotus groupware, which provides support for e-mail, Sametime (chat and e-meeting), team room (shared electronic workspace), and other applications.

Participants reported that e-mail was used more than any other medium of communication among GVT members. Participants in all GVTs perceived e-mail as a widely used communication channel; they reported that e-mail was used to address messages to individual team members, subgroups, or the entire team, and to communicate across team boundaries. It was evident from the interviews that e-mail was a standard medium of communication. E-mail was repeatedly mentioned as the most favorable channel for effective intercultural communication among dispersed members, despite its high cost of interaction due to the time it takes to type.

Two important aspects are to be considered regarding the benefits and limitations of e-mail in the context of GVTs. These are (a) the benefits and limitations that are innate in the technology and (b) the benefits and limitations of e-mail for 
intercultural communication. Innate benefits of e-mail technology include the capacity to support work at different times and places; limitations include the reduced capability of e-mail to convey social and nonverbal cues. In intercultural communication, however, the benefits of e-mail remain, while some of the limitations transform and become beneficial. More specifically, the lack of nonverbal and social cues reduces miscommunication due to cultural diversity. Thus, participants claimed that e-mail lessens the negative impact of cultural diversity and reduces intercultural miscommunication. This claim, which was made repeatedly by the participants, is illustrated in the following quote:

It's even easier as long as you use media like e-mail ... so I think the misinterpretation and the negative influence of cultural diversity is lower when trying to use short English e-mail. . . . I think with this e-mail, I experience less problems or negative effects due to the cultural diversity using the e-mail than when I had communication on the phone or face to face. (Germany)

\section{Language Accuracy}

Participants repeatedly stated that culture and language differences created communication challenges. In particular, the need for message accuracy required team members to invest more time and effort in the processes of encoding and decoding messages, thus increasing the cost of interaction for both the sender and receiver.

Participants claimed that the use of e-mail reduces miscommunication due to language differences among culturally diverse GVT members. They suggested that email enables normative English speakers to express themselves better than they can by talking:

They [Japanese] try very hard, and they take very seriously trying to be able to communicate and speak English to us. . . . So they, as is often the case with second languages, when you learn it, it's much easier to write and read it than it is to speak it and hear it. And so writing notes is, their notes are very coherent. It's not hard to read what they write, and they don't have problems reading what we write. So e-mail is very effective in that way. (United States)

Detailed descriptions were given by the participant trying to explain why and how the use of email is favored in this context and how it increases language accuracy of the messages and reduces challenges associated with unfamiliar accents.

\section{Reducing Miscommunication by Improving Language Accuracy}

Because the sender can rehearse by going over the message before it is transmitted, e-mail provides the ability for both native and nonnative speakers to improve the accuracy of their messages. Furthermore, using e-mail eliminates the vocal noise of nonnative accents. In addition, the use of a spell-checker can improve language accuracy for nonnative speakers. Finally, group efforts by members at the same location can improve the accuracy of encoding and decoding e-mails. The following quotes represent this mitigation of the negative effect of low language accuracy. 
A participant in the United States reported, "Because in e-mail. . . . when I am writing I read over and want to be explicit so I go back, and say this, this, and this." A participant in Israel said, "I would rather use e-mail because. . . I can use the spell checking and all those kinds of things." A team member in France concurred:

I knew that it would be very important that all of the information that we write in English is not ambiguous at all. . . I I spent a lot of time writing messages in English, trying to make sure that these messages would be clear enough and not ambiguous. . . . I would prepare an e-mail that I would deliver to the mailing list [of the entire GVT], and before sending this e-mail to the mailing list, I would ask my teammates [in the same physical location and from the same culture] if they agree with the statement.

A participant in Israel stated that e-mail reduced miscommunication that can be caused by the accents of nonnative speakers of English:

With the Japanese and the Chinese it is just like that. I mean even if it begins on the phone, eventually we ask them to do it all via e-mail. Because we just don't understand what they are saying. ... It is so that if it is someone from Japan, I'll select written media and not any other media because I can't understand what he is saying. When I was working on a specific project in Russia it was also more correct. I mean it was very difficult for them to talk, so I would send, I would use the written media.

Thus, miscommunication due to language barriers is reduced in GVTs that conduct most of their shared work using e-mail. E-mail enables rehearsal before sending a message and improves the accuracy of the message. In addition, it eliminates miscommunication due to unfamiliar accents.

\section{Verbal and Nonverbal Styles in Intercultural Communication}

Participants also suggested that e-mail mitigates the negative impact of differences in both nonverbal and verbal style that are involved in intercultural communication. Detailed descriptions and specific examples are provided next.

\section{Reducing Miscommunication Due to Differences in Intercultural Verbal Styles}

The differences in verbal style mentioned by GVT members corresponded to three out of the four stylistic modes of verbal interaction identified by Gudykunst and Ting-Toomey (1988): direct-indirect, succinct-elaborate, and contextual-personal. For example, Americans and Israelis said that GVT members from eastern cultures such as Japan were not direct in their communication, "because for one thing, Japanese, or Asians, are just, they don't like to say 'no'" (United States). The Germans and Japanese referred to English as more personal than their own language: "In Japan, maybe more complicated or strict expressions exist for how polite you are speaking.. . . That depends on the age of the person ... so conversation is the same unless there is an older person. With [an older team member], I would speak differently" (Japan). 
E-mail reduces, but does not eliminate, the negative impact of differences in verbal style. This reduction is first due to the use of "e-mail style," which is formal, technical, and structured, with short and precise sentences. Each message contains only one idea and includes the relevant context. The following quotes from interviews with participants illustrate this type of mitigation. These include examples for each of the three verbal styles and a general comment about "e-mail style".

An American team member remarked that e-mail allows an accurate and direct style that reduces the impact of direct-indirect differences in communication styles:

I think the Japanese tend to be more direct in e-mail or attempt to be. Because for one thing, Japanese, or Asians, are just, they don't like to say "no ". . . in fact, they're trying to say, "No, I don't agree with you, and you ought to think about it differently. " On the phone, it is hard; it is harder, so that's one of things that I found quite frustrating.

When using e-mail, team members are more likely to provide the context, thus reducing elaborate-succinct style differences. In the words of a participant in Israel,

E-mails usually lack context. . . One learns over time not to assume that the other one understands what the context is. So you will repeat all of the context, and then you add your own sentence. . . . Sometimes just in order to communicate one sentence, you need to write one page. . . . In any team. . . . any culture. ... you learn that you have to provide the context in e-mail.

E-mail also provides a verbal sequence that makes it unnecessary to interpret silence, as a team member from Israel pointed out:

One of the things that I am doing is to listen, which is very difficult with the Japanese. I can't ... [understand] them at all. I listen enough to know that I don't know anything. With the Japanese I know that I have no clue about how to communicate with them well. I have learned. . . but the Japanese they simply don't talk, you have nothing to listen to. So you would learn how to exchange messages with them. And today I am writing to them much better than I am talking with them for example.

For team members who are used to more formal language styles, the formality of written English provides a balance that reduces personal-contextual differences. A team member in Germany explained:

If it got very formal, in English, I have a problem, with written language to really use very, very formal English. The English language is by nature very informal compared to German. . . . In Germany, I am used to writing more formally than in the English language. ... When I'm talking about formal, I'm talking about the style. I'm not talking about content.

A participant in Israel reported that GVT members learned to use "e-mail style": 
One learns to use very simple language and short sentences. ... For example in an e-mail. . . . you will not include more than one idea. . . . If you have three different things to say you will do it in three separate messages. . . . I highly appreciate those who write on one subject, that appears in the subject line, with no additional subjects. . . . Since I observed it with the Indian, the Japanese, everyone learns slowly to behave in a universal way.

\section{Eliminating Miscommunication Due to Differences in Nonverbal Communication}

Another claim that the participants made is that e-mail eliminates the nonverbal miscommunication associated with face-to-face meetings, because differences in body language and in the approach toward public and private space are not manifested in intercultural communication via e-mail. A participant in the United States reported that

...communicating with technology [e-mail] with people in other countries, from my experience, removes some of the problems, to the extent that you don't have all the cultural, physical aspects of communications. You know, the way you speak to a Japanese is not the way you speak to an Arab is not the way you speak to an American, from the point of view of the distance you have to keep, the way you look at them, the way you express feeling, et cetera. When you just type a text in an e-mail or a chat system . . . all that disappears, there is just the plain text there.

To sum up, participants in this study claimed that e-mail enables them to improve language accuracy and to overcome differences in verbal and nonverbal styles of intercultural communication.

\section{DISCUSSION AND CONCLUSIONS}

Summarized conclusions, along with propositions that emerged from the data are presented next. These propositions could serve as a starting point for future studies that could test, validate, generalize, and refine them. Then, the limitations of this study will be described. Finally, implications for practice and suggestions for future research will be outlined.

This study suggests that intercultural miscommunication due to language, verbal cues, and nonverbal cues is mitigated by the use of e-mail. This effect decreases process losses due to miscommunication and therefore increases team productivity of heterogeneous teams that use email (compared with those that do not).

First, compared with spoken language, e-mail provides normative speakers with more potential for accurate word choice. This improvement is due to the rehearsability characteristic of the technology-that is, the ability to rehearse communication prior to the communication action (Dennis \& Valacich, 1999). Similarly, miscommunication is reduced because the accents of normative spoken language do not create this type of "noise" in a lean textual channel of communication such as e-mail. Therefore, the language problems that cause miscommunication are mitigated in the virtual setting. Thus, the following is proposed: 
P1: Miscommunication due to language differences is reduced in e-mail compared to face-to-face.

P1a: By providing the ability to edit, to rehearse, and to consult a dictionary or colleagues, e-mail improves language accuracy and reduces intercultural miscommunication.

Second, e-mail reduces the negative impact of differences in verbal style. The message is written in direct verbal style, and the verbal communication is also more accurate than it might be in spoken English. In addition, e-mail gives the text in a sequence that does not include "silence" or pauses for interpretations. This straightforward text helps overcome differences between succinct and elaborate verbal styles. However, the data does not provide any evidence for e-mail mitigation of the fourth verbal difference: that between affective-intuitive and instrumental styles. Thus, the following is proposed:

P2: By providing the ability to overcome differences in verbal style, e-mail reduces intercultural miscommunication compared to face-to-face.

P2a: A verbal sequence that omits the need to interpret silence reduces intercultural miscommunication.

P2b: Accurate and direct style reduces the impact of direct-indirect differences and reduces intercultural miscommunication.

P2c: Providing a context reduces elaborate-succinct differences and reduces intercultural miscommunication.

P2d: Balancing formality in written English reduces personal-contextual differences and reduces intercultural miscommunication.

Third, since intercultural nonverbal misunderstandings are not evident in the virtual setting, their negative effects are reduced. This is because most communication incidents between team members are conducted using lean media. These lean channels, such as e-mail, do not convey nonverbal cues; therefore, misunderstandings due to misinterpretation of nonverbal cues are reduced. Thus, the following is proposed:

P3: Because e-mail does not support nonverbal communication, intercultural miscommunication is minimized via e-mail compared to face-to-face.

Among the limitations of this study is the fact that the goal of the research-to contribute to the understanding of the effects of e-mail use on GVT effectiveness-was accomplished primarily in the context of one organization. Transference of these findings to other industries and even to other corporations in the same industry should be made with caution. The propositions are based on this specific context and should 
be tested, validated, and refined in other contexts and with other methods. For example, triangulation with additional data sources or with quantitative methods may increase the validity of the findings. Another limitation of this study is its sample, which included only a few members from some cultures (e.g., Japan, France, and Germany) and many from other cultures (the United States and Israel). The findings are probably skewed and primarily reflect perceptions held by members of the latter two cultures. Most of the participants were from western cultures, and they reported on difficulties of working with members of eastern cultures, which were barely represented in this sample. Future research should include members of eastern cultures, larger representation of each culture, and equal representation of members per culture in the sample. A final limitation of this study is the potential inconsistency between participants' reports about what they are doing and what they actually do.

Despite these limitations, this study contributes to our understanding of the impact of mediated communication, and e-mail in particular, on intercultural communication theories that have been developed in face-to-face contexts. The findings of this study suggest that e-mail mitigates the negative impact of cultural diversity on team intercultural communication and as a result improves team effectiveness. In today's multinational corporations, most intercultural communication is mediated via email. The use of e-mail reduces some of the differences in style and language that cause miscommunication (e.g., differences in verbal style) and eliminates others (e.g., nonverbal cues). Only future research can illuminate the extent of reduction that e-mail can provide.

This study has practical implications for GVT members training in intercultural communication; the findings suggest that training should focus more on differences in verbal styles and that when team members are dispersed, e-mail is an effective medium for intercultural communication. However, GVT members need to be able to communicate effectively in both face-to-face and mediated communication contexts.

\section{REFERENCES}

Adler, N. J. International dimensions of organizational behavior (3rd ed.). Boston: PWS-Kent, 1997.

Dafoulas, G., \& Macaulay, L. "Investigating cultural differences in virtual software teams," The ElectronicJournal of Information Systems in Developing Countries, 7(4), 1-14, 2001.

Daft, R. L., \& Lengel, R. H. "Organizational information requirements, media richness and structural design,"Management Science, 32, 554-572, 1986.

Daily, B. F., \& Steiner, R. L. "The influence of group decision support systems on contribution andcommitment levels in multicultural and culturally homogeneous decision-making groups," Computers in Human Behavior, 14(1), 147-162, 1998.

Daily, B., Whatley, A., Ash, S. R., \& Steiner, R. L. "The effects of a group decision support system on culturally diverse and culturally homogeneous group decision making," Information \& Management, 30, 281-289, 1996.

Dennis, A. R,, \& Valacich, J. S. "Rethinking media richness: Towards a theory of media synchronicity," Proceedings of the 32nd Hawaii International Conference on System Sciences, 1999. 
DeSanctis, G., Wright, M., \& Jung, L. "Building a global learning communication," Communications of theACM, 44(12), 80-82, 2001.

Dube, L., \& Pare, G. "Global virtual teams," Communications of the ACM, 44(12), 71-73, 2001.

Earley, P. C., \& Mosakowski, E. "Creating hybrid team cultures: An empirical test of transnational team functioning," Academy of Management Journal, 43(1), 26-49, 2000.

Evaristo, R. "The management of distributed projects across cultures," Journal of Global Information Systems, 17(4), 58-70, 2003.

Frank, J., \& Toland, J. "E-mail as a learning technology in the South Pacific: An evaluation," Education Technology \& Society, 5(3), 40-53, 2002.

Glaser, B., \& Strauss, A. The discovery of grounded theory: Strategies for qualitative research. Chicago: Aldine, 1967.

Gudykunst, W. B., \& Ting-Toomey, S. Culture and interpersonal communication. Newbury Park, CA: Sage Publications, 1988.

Hollingshead, A. B., McGrath, J. E., \& O'Connor, M. "Group task performance and communication technology: A longitudinal study of computer-mediated versus face-to-face work groups," Small Group Research, 24, 307-324, 1993.

Jackson, T.W., Dawson, R., \& Darren, W. "Understanding e-mail interaction increases organizational productivity," Communications of the ACM, 46(8), 80-84, 2003.

Jarvenpaa, S. L., \& Leidner, D. E. "Communication and trust in global virtual teams," Organization Science,10, 791-815, 1999.

Kayworth, T. R., \& Leidner, D. E. "Leadership effectiveness in global virtual teams," Journal of Management Information Systems, 18(3), 7-40, 2001.

Kirkman, B. L., Rosen, B., Gibson, C. B., Tesluk, P. E., \& McPherson, S. O. "Five challenges to virtual team success: Lessons from Sabre, Inc.," The Academy of Management Executives, 16(3), 67-69, 2002.

Klimoski, R., \& Mohammed, S. "Team mental model: Construct or metaphor?," Journal of Management, 20,403-437, 1994.

Lee, A. "Electronic mail as a medium for rich communication: An empirical investigation using hermeneuticinterpretation," MIS Quarterly, 18(2), 145-157, 1994.

Lee, O. "Cultural differences in e-mail use of virtual teams: A critical social theory perspective. Cyberpsychology \& Behavior, 5(3), 227-232, 2002.

Lipnack, J., \& Stamps, J. Virtual teams: Reaching across space, time and organizations with technology. New York: John Wiley \& Sons, 1997.

Markus, L. Electronic mail as the medium for managerial choice. Organization Science, 5, 502-527, 1994.

Massey, A. P., Hung, C. Y., Montoya-Weiss, M., \& Ramesh, V. "When culture and style aren't about clothes: Perceptions of task-technology "fit" in GVTs," In Proceedings of the 2001 International ACM SIGGROUPConference on Supporting Group Work (pp. 207-213), 2001.

Maznevski, M.L., Chudoba, K. M. Bridging space over time: Global virtual team dynamics and effectiveness. Organization Science, 11, 473-492, 2000.

McLeod, P. L., \& Lobel, S.A. "The effects of ethnic diversity on idea generation in 
small groups," In Academy of Management Annual Meeting Best Papers Proceedings (pp. 227-231), 1992.

Miles, M. B., \& Huberman, M. A. Qualitative analysis: An expanded sourcebook (2nd ed.). Thousand Oaks, CA: Sage, 1994.

Oetzel, J.G. "Self-constructs, communication processes, and group outcomes in homogeneous and heterogeneous groups," Small Group Research, 32(1), 1954, 2001.

Pauleen, D. J. "Lessons learned crossing boundaries in an ICT-supported distributed team," Journal of Global Information Management, 11(4), 1-19, 2003.

Schmitz, J., \& Fulk, J. "Organizational colleagues, media richness, and electronic mail," Communication Research, 75,487-523, 1991.

Sproull, L., \& Keisler, S. "Reducing social context cues: Electronic mail in organizational communication," Management Science, 32, 1492-1513, 1986.

Suchan, J., \& Hayzak, G. "The communication characteristics of virtual teams: A case study.," IEEE Transactions on Professional Communication, 44(3), 174186, 2001.

Watson, W. E., Kumar, K., \& Michaelson, L. K. "Cultural diversity's impact on interaction process and performance: Comparing homogeneous and diverse task groups," Academy of Management Journal, 36,590-602, 1993.

Watson-Manheim, M. B., \& Belanger, F. "Exploring communication-based work processes in virtual work environments," Proceedings of the 35th Hawaii International Conference on System Sciences, 2002.

\section{KEYWORDS}

Intercultural Communication, Global Virtual Teams, E-mail, ComputerMediated Communications, Cultural Diversity. 